Article

\title{
The Effect of Dynamic Recrystallization on Monotonic and Cyclic Behaviour of Al-Cu-Mg Alloy
}

\author{
Adam Tomczyk*, Andrzej Seweryn and Małgorzata Grądzka-Dahlke \\ Faculty of Mechanical Engineering, Białystok University of Technology, Wiejska 45C Str., 15-351 Białystok, \\ Poland; a.seweryn@pb.edu.pl (A.S.); m.dahlke@pb.edu.pl (M.G.-D.) \\ * Correspondence: a.tomczyk@pb.edu.pl
}

Received: 30 April 2018; Accepted: 21 May 2018; Published: 23 May 2018

\begin{abstract}
The paper presents an investigation that was conducted to determine the possibility of the occurrence of the process of dynamic recrystallization in 2024 alloy during monotonic tensile and creep tests at the elevated temperatures of $100{ }^{\circ} \mathrm{C}, 200{ }^{\circ} \mathrm{C}$, and $300{ }^{\circ} \mathrm{C}$. As-extruded material was subjected to creep process with constant force at elevated temperatures, until two varying degrees of deformation were reached. After cooling at ambient temperature, the pre-deformed material was subjected to monotonic and fatigue tests as well as metallographic analysis. The process of dynamic recrystallization was determined in monotonic tests to occur at low strain rate $(0.0015 / \mathrm{s})$ only at the temperature of $300^{\circ} \mathrm{C}$. However, in the creep tests, this process occurred with varying efficiency, both during creep at $200{ }^{\circ} \mathrm{C}$ and $300^{\circ} \mathrm{C}$. Dynamic recrystallization was indicated to have a significant influence on the monotonic and cyclic properties of the material.
\end{abstract}

Keywords: dynamic recrystallization; mechanical behaviour; creep pre-deformation; fatigue life

\section{Introduction}

EN AW-2024 aluminium alloy is one of the most typically and frequently used of the entire $\mathrm{Al}-\mathrm{Cu}-\mathrm{Mg}$ alloy group. This alloy is frequently applied whenever a beneficial ratio of strength to weight is required. Frequently, these applications are connected with the aircraft industry (e.g., plating of wings or fuselages of the aircrafts). The areas that are most vulnerable to fractures, such as rivet bores, are frequently subjected to cold expansion, which leads to the generation of residual stress and increase in fatigue life [1]. High cruising speed at high altitudes causes the material to heat up to even $120^{\circ} \mathrm{C}$ [2]. This promotes creep of the material and stress relaxation, which directly leads to a decrease in fatigue life. However, aluminium alloys may also operate at higher temperatures, and hence are commonly used for the housings of low-speed coreless generators in wind turbines. During the operation of such generator, at peak power, its temperature may reach ca. $250{ }^{\circ} \mathrm{C}$ [3]. Due to the impact of centrifugal forces at increased temperature, the creep process may occur. As a result of such loads, the material changes its properties and its further operation may lead to damage. This change is an effect from a joint impact of the mechanical and thermal loads. Factors such as temperature, strain rate, duration of load, etc. are gaining pivotal significance.

Favourable loading conditions at increased temperature may trigger the process of dynamic recrystallization in the alloy. This significantly affects subsequent mechanical properties of the material, in the case of both monotonic and cyclically varying loads. The recrystallization process of aluminium alloys is constantly undergoing study (e.g., [4-6]). Essentially, three types of dynamic recrystallization are distinguished: discontinuous (DDRX)-referring to the nucleation and increase in the size of grains; continuous (CDRX) - referring to the transition of grains with low angle misorientation to grains with high angle misorientation; and geometric (GDRX)—referring to the fragmentation of primary grains [6-8]. In the vast majority of aluminium alloys, the dominating mechanism of 
dynamic recrystallization is CDRX. This process occurs primarily in the case of small primary grains, large precipitation particles, and significant strains [9]. Less-common cases of the DDRX mechanism occurring in aluminium alloys have also been documented [10-12].

The process of dynamic recrystallization is significantly affected by temperature, strain level, and strain rate. The fractions with high misorientation angle grow significantly with increase in strain [7]. Even if the percentage of random boundaries is low before deformation, it increases gradually with strain by DRX during deformation $[13,14]$. Comparison of dynamic recrystallization test results during compression and torsion showed that the strain path does not noticeably alter the DRX kinetics. A DRX process is usually initialized by higher temperature and lower strain rates [15-17]. In the case of a constant temperature, the possibility of recrystallization is strongly related to the strain rate $[18,19]$ - a specific strain rate can be observed, below which the DRX does not occur. The non-homogenous distribution of the particles in the vicinity of grain boundaries led to boundary migration caused by the strain [15]. The primary cause of this recrystallization is high dislocation density generated in the close vicinity of these particles [20-22]. Additionally, it was observed that complete recrystallization at higher temperature requires lower strain values. A similar correlation was observed in a composite material, where microstructure was obtained with equiaxial grains and high dislocation density [23]. It was found that a lower limit to the processing temperature for the formation of ultra-fine grain structures can be imposed by a low grain boundary mobility [24]. An upper limit can be imposed by grain growth.

Dynamic recrystallization can clearly improve the mechanical properties of the material. This was demonstrated in an alloy obtained by the moderate strain condition imposed by hot extrusion [10]. Here, discontinuous DRX exhibited both high yield stress and elongation. The technology used to manufacture the alloy is also of great significance. The same aluminium alloy obtained by powder metallurgy (PM) may have completely different properties at elevated temperature from the alloy obtained by ingot metallurgy (IM) $[13,14]$. It was found that a DRX process occurred during deformation in the PM alloy, and static recrystallization occurred in the IM alloy before deformation. Dynamic recrystallization and dynamic recovery (DRV) can also lead to the softening of aluminium alloys at elevated temperature and at different strain rates [19]. However, at lower strain rate, the softening is caused by CDRX, whereas it is caused by DRV at higher strain rate. This stems from the fact that the average misorientation parameter value does not change in the latter case.

A totally recrystallized structure in aluminium alloys can be obtained using different techniques. One of the most popular is equal channel angular extrusion (ECAE) [25]. The structure obtained by this method usually contains grains with an average size of $0.9 \mu \mathrm{m}$ and relatively low dislocation density. The process of continuous dynamic recrystallization continued in a uniform manner. New grains were formed both along the boundaries of parent grains and inside the existing grains. As was also demonstrated, during the ECAE extrusion, the best results were obtained with constant strain path [26]. The process of microstructural transformations during ECAE can be divided into three stages [27,28]: (1) the formation of classic dislocation structures accompanied by the creation of deformation bands; (2) the growth of large deformation bands leading to the fragmentation of grains; (3) the final growth of new grains. In [29], isothermal rolling after ECAE process was demonstrated to cause an increment in fractions with high misorientation angle, thus further improving the plasticity of the material. The three-stage character of the microstructural transformations was also confirmed [30] for alloy subjected to compression in several directions. Frequently, the process of high-pressure torsion (HPT) is used to obtain a recrystallized structure in different alloys [31-34]. It brings about additional interesting observations related to the behaviour of the material's microstructure. The cited papers irrefutably prove that severe plastic deformation (SPD) can not only cause grain refinement, but also accelerates the mass transfer process [33]. In order to analyse such states, information is required regarding, for example, the concentration of a second component in solution, activation enthalpy of bulk tracer diffusion, etc. The HPT technique can lead to the formation of nanostructures which are further from the equilibrium state than the initial coarse-grained material [32]. 
This paper is focused on the effects connected to the influence of dynamic recrystallization on monotonic and cyclic properties of 2024 aluminium alloy. The possibility of dynamic recrystallization occurring in conditions of monotonic tension and creep tests at the temperatures of $100{ }^{\circ} \mathrm{C}, 200{ }^{\circ} \mathrm{C}$, and $300^{\circ} \mathrm{C}$ was analysed. A constant low strain rate of $0.0015 / \mathrm{s}$ was used for this purpose. The creep process at the increased temperatures and constant force was continued until two various degrees of strain were obtained. The material with pre-deformation was subjected to a metallographic analysis, monotonic tensile tests, and low-cycle fatigue. The results of the analysis were compared to the results obtained for as-extruded material.

\section{Materials and Methods}

The EN AW-2024 aluminium alloy was used in this investigation. The samples (Figure 1) were made from extruded rods with a length of $3 \mathrm{~m}$ and diameter of $16 \mathrm{~mm}$. The chemical composition is presented in Table 1. The gauge diameter of the sample was $6.5 \mathrm{~mm}$, and the gauge length was $13 \mathrm{~mm}$. The total length of the sample and the length of the screwed parts were $126 \mathrm{~mm}$ and $31 \mathrm{~mm}$, respectively. The structure of the analysed alloy, clearly directed due to the extrusion process, is presented in Figure 2. Keller's reagent $\left(1.5 \% \mathrm{HCl}+1 \% \mathrm{HF}+2.5 \% \mathrm{HNO}_{3}+95 \% \mathrm{H}_{2} \mathrm{O}\right)$ was used in the etching process.

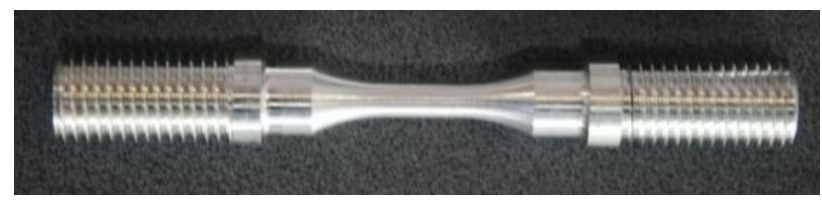

Figure 1. Sample used in monotonic tensile and creep tests.

Table 1. Chemical composition of analysed alloy [35].

\begin{tabular}{ccccccccc}
\hline Component & Si & Fe & Cu & Mn & Mg & Cr & Zn & Ti \\
\hline Amount (\%) & 0.13 & 0.25 & 4.4 & 0.62 & 1.7 & 0.01 & 0.08 & 0.05 \\
\hline
\end{tabular}

a)

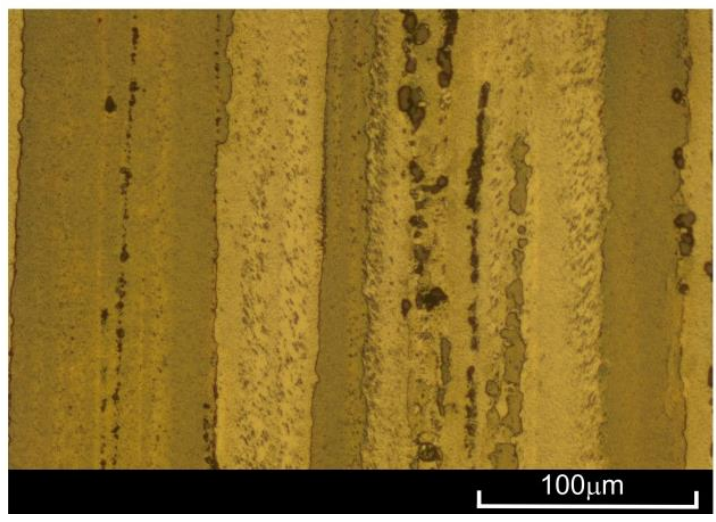

b)

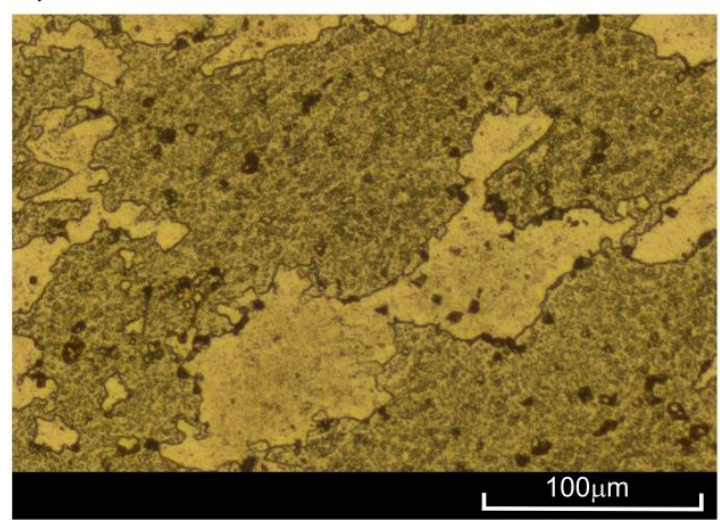

Figure 2. Structure of as-extruded 2024 aluminium alloy in: (a) longitudinal; (b) transverse cross-section.

The samples used in the monotonic tension and creep tests were identical in shape and size. The fastened part of the samples was screwed, as required by the creep testing machine. The monotonic tension and creep tests were conducted using the Kappa 100 SS creep testing machine manufactured by Zwick/Roell (Ulm, Germany). The machine can be used to perform tests of creep, creep rupture, monotonic tension, and stress relaxation. The creep testing machine was controlled with the specialized software testXpert II v3.6. 
For analysis at increased temperature, a three-zone furnace manufactured by Maytec Mess und Regeltechnik GmbH (Singen, Germany) was used, with temperature range of up to $900{ }^{\circ} \mathrm{C}$, with a universal Zwick/Roell controller. The furnace is equipped with six thermocouples, three of which are installed on furnace walls inside its working space. The other three thermocouples were mounted on the sample. This enabled recording of the temperature in three different places on the sample as well as the temperature of the furnace. The sample was placed inside the furnace using special high-temperature (up to $1200^{\circ} \mathrm{C}$ ) strings.

A specifically designed and built device was used to measure the strains [36]. This device allows the sample strain to be measured using any device (e.g., extensometer) that can be used for strain measurement at room temperature. The Epsilon 3542050M-50-ST axial extensometer (Epsilon Technology Corp., Jackson, WY, USA) with varying gauge length of 25/50 mm and range of $+25 \mathrm{~mm}$ and $-5 \mathrm{~mm}$ was used in cooperation with the aforementioned device.

In fatigue tests, the servo-hydraulic Material Testing System (MTS) 322 with range of axial force of $\pm 50 \mathrm{kN}$ was used. The strain measurements were taken using an Instron 2620-601 dynamic extensometer (Instron, Norwood, MA, USA) with gauge length of $12.5 \mathrm{~mm}$ and range of $\pm 5 \mathrm{~mm}$. The fatigue tests were conducted at room temperature $\left(20^{\circ} \mathrm{C}\right)$ with frequency of $f=0.2 \mathrm{~Hz}$ and cycle asymmetry coefficient of $S=\varepsilon_{\min } / \varepsilon_{\max }=-1$ [37]. The samples used in the fatigue tests were different from those used in the creep and tensile tests only in their lack of a thread at the gripped section.

\section{Results and Discussion}

\subsection{Tests of Monotonic Tensile, Creep-Rupture, and Creep}

In tests of monotonic tension and creep at increased temperatures, samples were heated to different temperatures at various rates, as presented in Table 2 . Set temperatures were achieved with a precision of $\pm 2{ }^{\circ} \mathrm{C}$. It should be noted that before the start of the test, the samples remained in the furnace until reaching the set temperature. The heating rate and period of sample remaining in the furnace ensured that the required temperature was achieved in the whole gauge area. It must be noted that the data in Table 2 only describe the heating history of the sample in the furnace. The heating rates remained in accordance with the manufacturer's recommendations.

Table 2. Sample heating rates used in analyses and estimated time of heating to obtain set temperatures.

\begin{tabular}{ccc}
\hline Set Temperature $\left({ }^{\circ} \mathbf{C}\right)$ & Heating Rate $\left({ }^{\circ} \mathbf{C} / \mathbf{m i n}\right)$ & Estimated Time of Heating (min) \\
\hline 100 & 3 & $170( \pm 5)$ \\
200 & 5 & $120( \pm 3)$ \\
300 & 8 & $100( \pm 2)$ \\
\hline
\end{tabular}

In order to determine the basic mechanical properties of the material at elevated temperature $\left(100{ }^{\circ} \mathrm{C}, 200{ }^{\circ} \mathrm{C}, 300{ }^{\circ} \mathrm{C}\right)$ as well as at room temperature $\left(20^{\circ} \mathrm{C}\right)$, the monotonic tensile tests were performed on a series on three samples at each temperature, in accordance with $[38,39]$. The strain rate of gauge length in these tests was $0.0015 / \mathrm{s}$. The results in the form of true tension curves $\left(\sigma_{1}, \varepsilon_{1}\right)$ and $\left(\sigma_{\text {eq }}, \varepsilon_{\mathrm{eq}}\right)$ are presented in Figure 3 . These curves were obtained through numeric calculations using the finite element method including experimental correlations between the force and elongation of the gauge length. The applied procedure was identical to the one presented in the paper by Derpeński and Seweryn [40], which allowed for the determination of maximal principal stress and strain $\sigma_{1}$ and $\varepsilon_{1}$ as well as equivalent stress and strain $\sigma_{\text {eq }}$ and $\varepsilon_{\text {eq. }}$. The MSC.Marc software (release 2010) package was used for these simulations. The elastic-plastic material model with isotropic hardening and the Huber-von Mises yield criterion was applied in this procedure. The hardening curve until neck formation was taken directly from the results of the experiment. The remaining part of the curve was determined on the basis of iterative calculations accounting for the necking effect. A nominal hardening curve was initially assumed, followed by load values and their corresponding displacement values 
being determined and then compared to the values obtained in the experiment. Next, the obtained curve was corrected and iterations progressed until the shape of the load-displacement curve from numerical simulations fitted the actual curve. This enabled the determination of both principal stress and strain $\left(\sigma_{1}, \varepsilon_{1}\right)$ as well as equivalent stress and strain $\left(\sigma_{\text {eq }}, \varepsilon_{\text {eq }}\right)$ according to the Huber-von Mises hypothesis. In Figure 3, two different true stress-strain curves $\sigma_{1}\left(\varepsilon_{1}\right)$ and $\sigma_{\text {eq }}\left(\varepsilon_{\text {eq }}\right)$ are shown. The distributions of stress (or strain) $\sigma_{1}\left(\varepsilon_{1}\right)$ and $\sigma_{\mathrm{eq}}\left(\varepsilon_{\mathrm{eq}}\right)$ prove that the principal stress (or principal strain) in the axis of the sample, in the moment of rupturing, exceeded the equivalent stress (equivalent strain). This correlates closely with the character of the surface of the fractures-the number and shape of the remnants of pores. This serves as the basis for the description of failure mechanism during monotonic tensile and creep tests. The values of basic parameters such as Young's modulus, yield stress $\sigma_{\mathrm{y}}$, ultimate tensile strength $\sigma_{\mathrm{u}}$, maximal strain $\varepsilon_{\mathrm{u}}$ corresponding to $\sigma_{\mathrm{u}}$, and nominal strain at break $\varepsilon_{\mathrm{B}}$ are presented in Table 3 [41]. It must be noted that the values $\sigma_{\mathrm{C}}$ and $\varepsilon_{\mathrm{c}}$ correspond to values of principal stress and strain $\sigma_{1}$ and $\varepsilon_{1}$ obtained based on true tension curves.

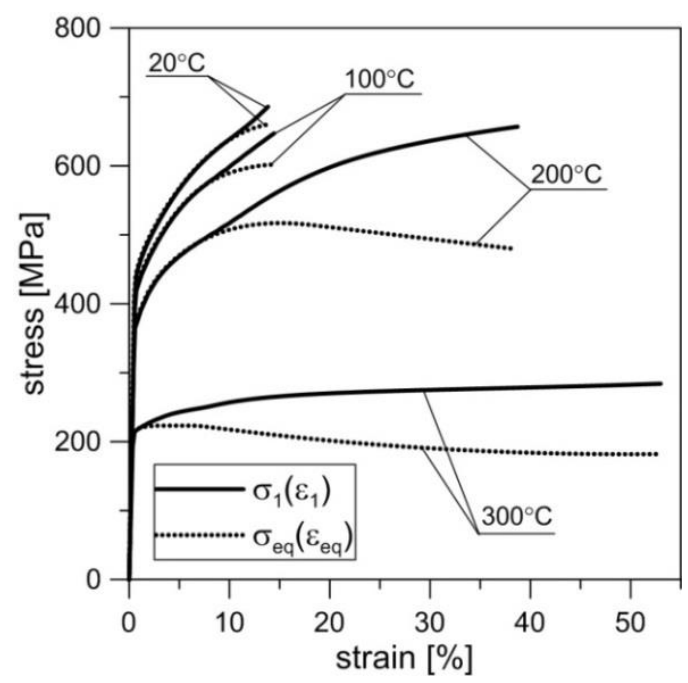

Figure 3. True stress-strain curves of monotonic tension $\sigma_{1}=\sigma_{1}\left(\varepsilon_{1}\right)$ and $\sigma_{\text {eq }}=\sigma_{\text {eq }}\left(\varepsilon_{\text {eq }}\right)$ of 2024 aluminium alloy obtained at various temperatures for as-extruded material.

Table 3. Values of basic strength parameters of 2024 aluminium alloy and value of critical stress and strain $\sigma_{\mathrm{c}}, \varepsilon_{\mathrm{c}}[42]$.

\begin{tabular}{cccccccc}
\hline $\boldsymbol{T}\left({ }^{\circ} \mathbf{C}\right)$ & $\boldsymbol{E}(\mathbf{G P a})$ & $\left.\sigma_{\mathbf{y}} \mathbf{( M P a}\right)$ & $\left.\sigma_{\mathbf{u}} \mathbf{( M P a}\right)$ & $\sigma_{\mathbf{c}}(\mathbf{M P a})$ & $\mathcal{E}_{\mathbf{u}}(\mathbf{\%})$ & $\varepsilon_{\mathbf{B}}(\mathbf{\%})$ & $\varepsilon_{\mathbf{c}}(\%)$ \\
\hline 20 & 74 & 447 & 580 & 686 & 12.1 & 13.3 & 13.8 \\
100 & 71 & 418 & 536 & 647 & 10.3 & 12.7 & 14.5 \\
200 & 70 & 372 & 460 & 657 & 9.1 & 19.8 & 38.7 \\
300 & 56 & 214 & 219 & 283 & 2.1 & 17.0 & 52.9 \\
\hline
\end{tabular}

As the temperature increased, the values of the basic mechanical parameters of analysed alloy, such as Young modulus $E$, yield stress $\sigma_{\mathrm{y}}$, and ultimate tensile strength $\sigma_{\mathrm{u}}$, decreased. This decrease was relatively small at $100^{\circ} \mathrm{C}$ and very significant at $300^{\circ} \mathrm{C}$. At the same time, the percentage elongation $\varepsilon_{\mathrm{u}}$, corresponding to $\sigma_{\mathrm{u}}$, decreased with the increase in the temperature, whereas percentage elongation at break $\varepsilon_{\mathrm{B}}$-increased. This indicates the increase in ductility of the material from the moment of strain localization and the formation of a neck up to rupture.

The observations of the microstructure of the sample ruptured at the temperatures of $20{ }^{\circ} \mathrm{C}, 100{ }^{\circ} \mathrm{C}$, and $200{ }^{\circ} \mathrm{C}$ (Figure 4a) did not present significant changes in comparison to as-extruded material (Figure 2). Let us note that all samples for microstructure observation were taken from the area just below the surface of the fracture in the neighbourhood of the sample axis. However, in the case of 
samples ruptured at $300{ }^{\circ} \mathrm{C}$, clear changes in microstructure were visible (Figure $4 \mathrm{~b}$ ). As a result of the strain at high temperature, fine equiaxial grains appeared, indicating the occurrence of dynamic recrystallization. New grains appeared mostly on the boundaries of large primary grains, deformed in the direction of loading. The short heating period at elevated temperature did not allow for full recrystallization of the material.

a)

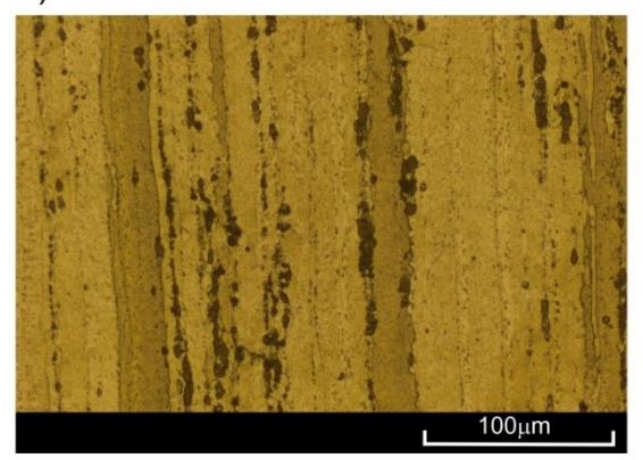

b)

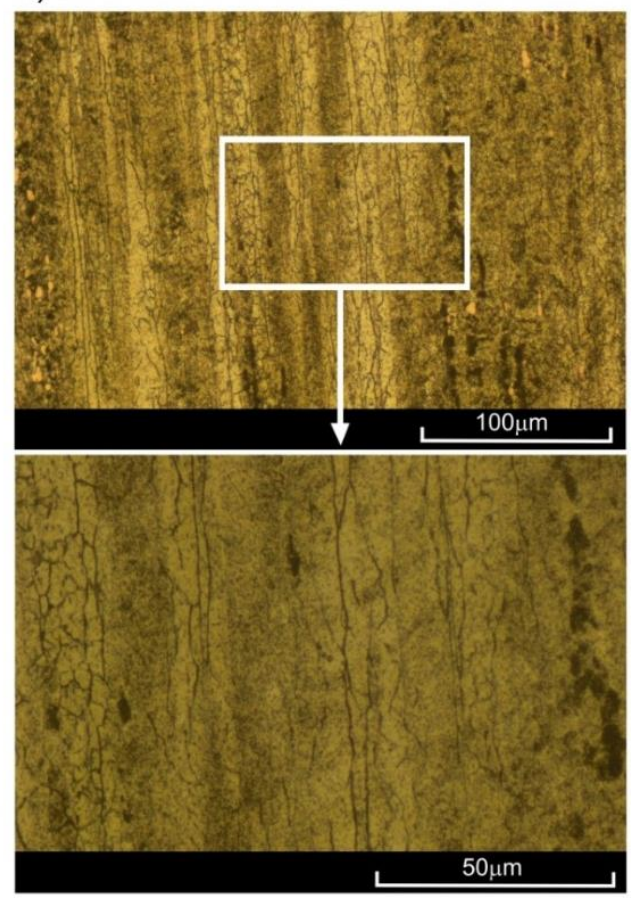

Figure 4. Microstructure of 2024 aluminium alloy subjected to tension at temperatures of (a) $200{ }^{\circ} \mathrm{C}$, (b) $300{ }^{\circ} \mathrm{C}$, and cooling at ambient temperature.

The paper by Tomczyk et al. [41] presents a detailed description of the scanning electron microscope (SEM) fractures of samples obtained by monotonic tension at room and elevated temperatures. The crack initiation process seemed to occur at every temperature at the axis of the sample. The fracture surface had a bi-planar nature, with the central part being a plane perpendicular to the axis. The numerical calculations clearly indicate that the principal stress $\sigma_{1}$ or principal strain $\varepsilon_{1}$ were dominating on this plane. The initiation of damage usually occurred on the boundary of the coarse precipitation and matrix or on the grain boundaries. The increase in the load led to the deformation of thus-created pores in the direction of the stress $\sigma_{1}$. The neighbouring pores created larger voids. At higher temperatures, the remains of the pores were more elongated towards the sample axis. The share of the area described in the whole cross-section increased with increasing temperature. The second of the mentioned planes connected the central area with the outer surface of the sample and rested at an angle of about $45^{\circ}$ to the sample axis, with the maximal shear stress dominating in the area. The fracture process occurred much faster and consisted of the sudden rupturing of bridges between the pores. In the case of relatively low temperature $\left(20^{\circ} \mathrm{C}, 100^{\circ} \mathrm{C}\right)$, this surface was dominant.

The results obtained from the monotonic tensile tests allowed for the establishment of loads in the creep tests at various elevated temperatures. At $100{ }^{\circ} \mathrm{C}$, the constant force of $17.55 \mathrm{kN}$ was selected, which constituted 1.27 of $\sigma_{\mathrm{y}}$ at that temperature. At temperatures of $200{ }^{\circ} \mathrm{C}$ and $300{ }^{\circ} \mathrm{C}$, these forces were $9.26 \mathrm{kN}\left(0.75 \sigma_{\mathrm{y}}\right)$ and $3.06 \mathrm{kN}\left(0.45 \sigma_{\mathrm{y}}\right)$, respectively. The creep tests were performed in accordance with [43] at a loading speed of $0.0015 / \mathrm{s}$. In order to remove any clearances in the grip-pull rod sample system, a preload of up to $50 \mathrm{~N}$ was applied prior to the application of proper force. The analysis was conducted on a series of four samples at each temperature, and then the results 
in the form of creep curves were averaged by time (Figure 5). The character of sample fractures after the creep rupture at various temperatures confirmed the increase in material ductility with the increase in temperature [42]. The character of these fractures was similar to the fractures obtained in monotonic tensile tests (Figure 6). However, the share of surface perpendicular to the sample axis was notably higher in the case of creep.

a)

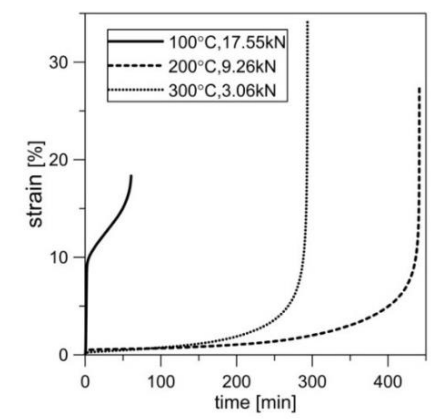

c)

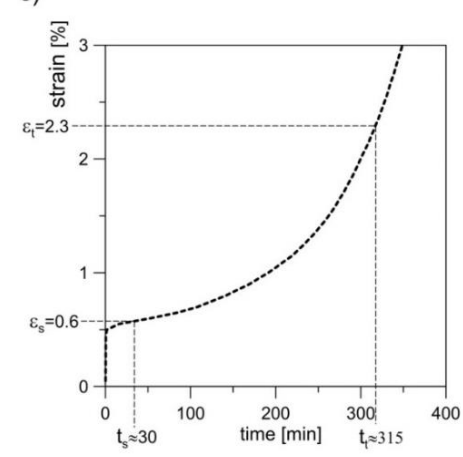

b)

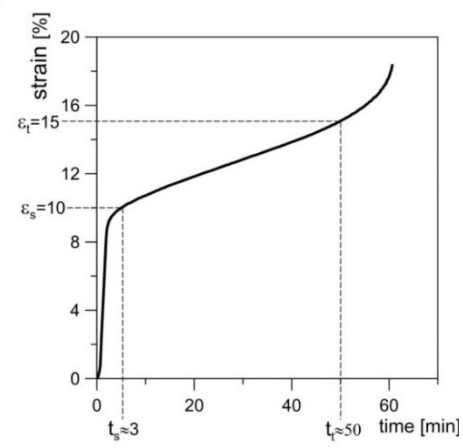

d)

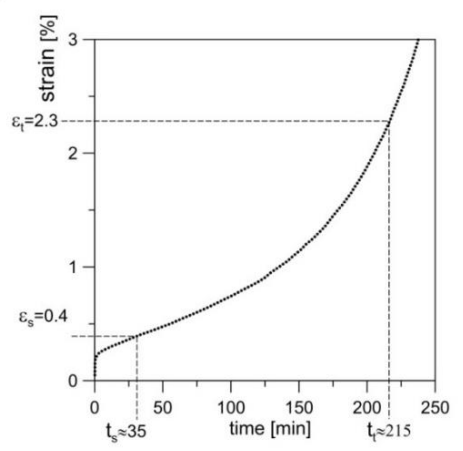

Figure 5. (a) Creep-rupture curves of 2024 aluminium alloy obtained in various temperatures and estimated values of time of creep before strain $\varepsilon_{\mathrm{s}}$ and $\varepsilon_{\mathrm{t}}$ for: (b) $100{ }^{\circ} \mathrm{C}, 17.55 \mathrm{kN}$; (c) $200{ }^{\circ} \mathrm{C}, 9.26 \mathrm{kN}$; (d) $300{ }^{\circ} \mathrm{C}, 3.06 \mathrm{kN}$.
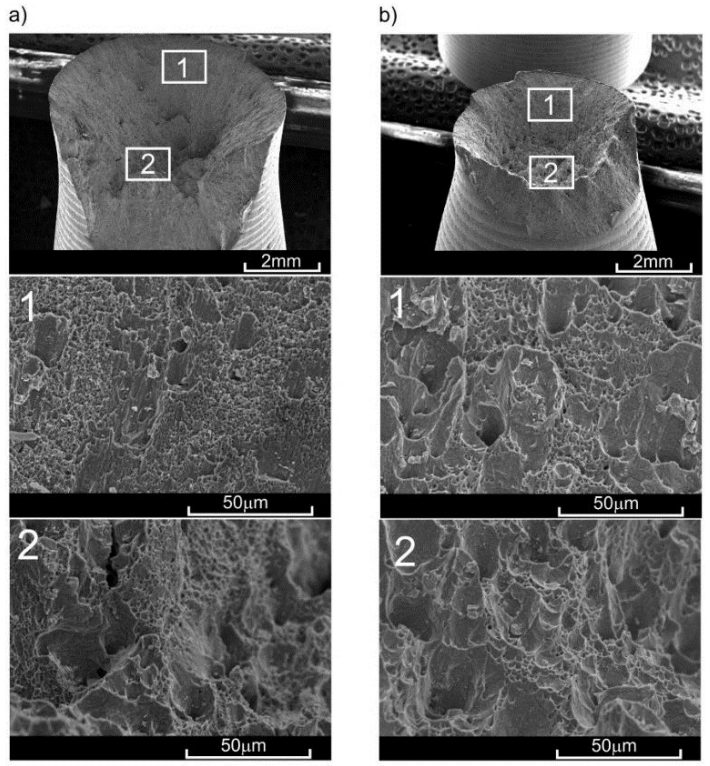

Figure 6. View of fractures obtained in (a) monotonic tensile test and (b) creep test at a temperature of $200{ }^{\circ} \mathrm{C}$ for as-extruded material. 
The strain level for creep pre-deformation was determined based on the average creep curves. Two different strain levels were selected. The idea was that the smaller deformation $\varepsilon_{\mathrm{s}}$ corresponds to the beginning of the second creep stage. It is worth noting that in the case of creep curves at $200{ }^{\circ} \mathrm{C}$ and $300{ }^{\circ} \mathrm{C}$, the second stage was not "perfectly" stable. The value of $\varepsilon_{\mathrm{s}}$ was therefore assumed immediately after the rapid decrease in creep rate (i.e., after reaching the given constant loading). The choice of larger deformation $\left(\varepsilon_{\mathrm{t}}\right)$ was encouraged by the need to achieve a specific strain close to the end of the secondary creep and the beginning of the tertiary creep. The values of loads during pre-deformation at elevated temperatures were identical to those of creep-rupture tests. At $100{ }^{\circ} \mathrm{C}$, this load equalled $17.55 \mathrm{kN}$, at $200{ }^{\circ} \mathrm{C}-9.26 \mathrm{kN}$, and at $300{ }^{\circ} \mathrm{C}-3.06 \mathrm{kN}$. The pre-deformation levels were as follows: for $100{ }^{\circ} \mathrm{C}-\varepsilon_{\mathrm{s}}=10 \%, \varepsilon_{\mathrm{t}}=15 \%$; for $200{ }^{\circ} \mathrm{C}-\mathcal{E}_{\mathrm{s}}=0.6 \%, \varepsilon_{\mathrm{t}}=2.3 \%$; for $300{ }^{\circ} \mathrm{C}-\varepsilon_{\mathrm{s}}=0.4 \%, \varepsilon_{\mathrm{t}}=2.3 \%$. The process of preliminary creep was conducted in one series of samples at given temperature and given load until $\varepsilon_{\mathrm{s}}$ was obtained, whereas in the other series it was conducted until $\varepsilon_{\mathrm{t}}$ was obtained. The period of sample creep until obtaining $\varepsilon_{\mathrm{s}}$ and $\varepsilon_{\mathrm{t}}$ strains was $t_{\mathrm{s}}$ and $t_{\mathrm{t}}$, respectively (Figure 5). The unloading of the sample gauge after reaching the set strain levels took place at a speed of $0.003 / \mathrm{s}$. Cooling of the samples was conducted in open air at room temperature. The strain values $\varepsilon_{\mathrm{S}}$ and $\varepsilon_{\mathrm{t}}$ varied depending on the temperature at which the tests were conducted. Ultimately, two series of pre-deformed samples were obtained per set temperature with each series containing four samples. Three samples from every series were subjected to monotonic tensile tests in order to determine basic mechanical properties [41,42]. The values of these parameters are presented in Table 4. In Figure 7 , true curves of monotonic tension $\sigma_{1}=\sigma_{1}\left(\varepsilon_{1}\right)$ are presented as obtained at room temperature for samples previously subjected to pre-straining at various temperatures and for two different strain levels. The last sample of each series was used for performing sections in order to observe the evolution of microstructure (Figures 8 and 9).

Table 4. Values of basic strength parameters of 2024 aluminium alloy and values of critical stress and strain $\sigma_{\mathrm{C}}, \varepsilon_{\mathrm{C}}$ for materials with varying history of pre-deformation [41].

\begin{tabular}{|c|c|c|c|c|c|c|c|c|c|}
\hline \multicolumn{3}{|c|}{ Pre-Deformation Condition } & \multirow{2}{*}{$E$ (GPa) } & \multirow{2}{*}{$\begin{array}{c}\sigma_{\mathbf{y}} \\
(\mathbf{M P a})\end{array}$} & \multirow{2}{*}{$\begin{array}{c}\sigma_{\mathbf{u}} \\
(\mathrm{MPa})\end{array}$} & \multirow{2}{*}{$\begin{array}{c}\sigma_{\mathrm{c}} \\
(\mathrm{MPa})\end{array}$} & \multirow{2}{*}{$\varepsilon_{\mathbf{u}}(\%)$} & \multirow{2}{*}{$\mathcal{E}_{\mathrm{B}}(\%)$} & \multirow{2}{*}{$\mathcal{E}_{\mathrm{c}}(\%)$} \\
\hline$T\left({ }^{\circ} \mathrm{C}\right)$ & $\varepsilon_{\mathrm{s}}(\%)$ & $\varepsilon_{t}(\%)$ & & & & & & & \\
\hline \multirow{2}{*}{100} & 10 & - & 72 & 598 & 610 & 680 & 4.6 & 5.3 & 7.1 \\
\hline & - & 15 & 72 & 635 & 640 & 673 & 2.7 & 2.7 & 3.5 \\
\hline \multirow{2}{*}{200} & 0.6 & - & 74 & 475 & 550 & 716 & 7.9 & 13.9 & 20.8 \\
\hline & - & 2.3 & 74 & 443 & 490 & 642 & 4.9 & 13.1 & 25.3 \\
\hline \multirow{2}{*}{300} & 0.4 & - & 71 & 255 & 363 & 518 & 7.1 & 17.9 & 36.5 \\
\hline & - & 2.3 & 73 & 186 & 316 & 380 & 8.7 & 13.1 & 15.2 \\
\hline
\end{tabular}

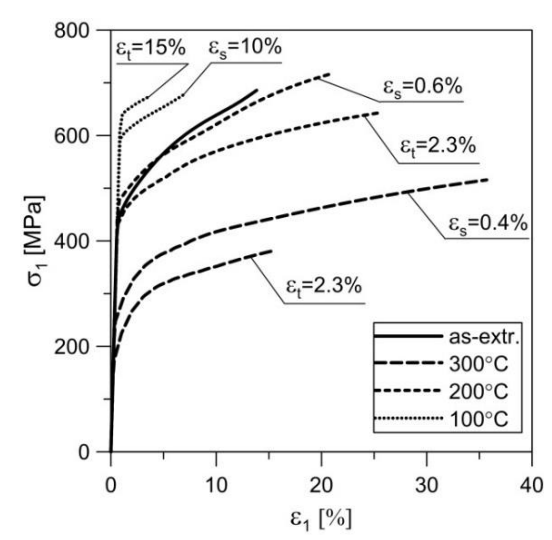

Figure 7. True curves of monotonic tension of 2024 aluminium alloy obtained for samples subjected to creep pre-deformation at various temperatures and with varying degrees of strain compared with tension curve for as-extruded material. 
a)

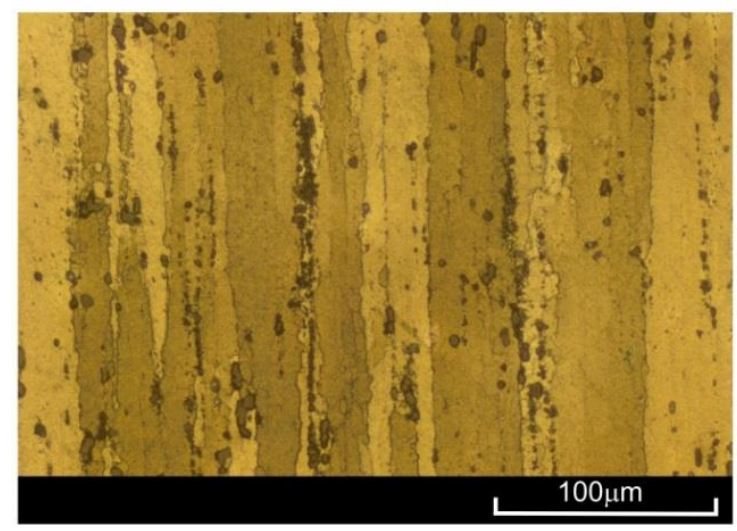

b)

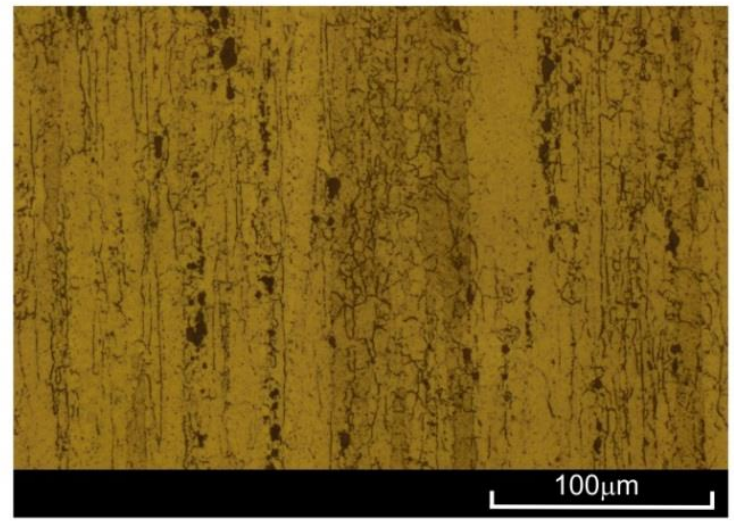

Figure 8. Microstructure of 2024 aluminium alloy subjected to creep at $200{ }^{\circ} \mathrm{C}$ until strain of: (a) $\varepsilon_{\mathrm{s}}=0.6 \%$; (b) $\varepsilon_{\mathrm{t}}=2.3 \%$, cooled at ambient temperature.

a)
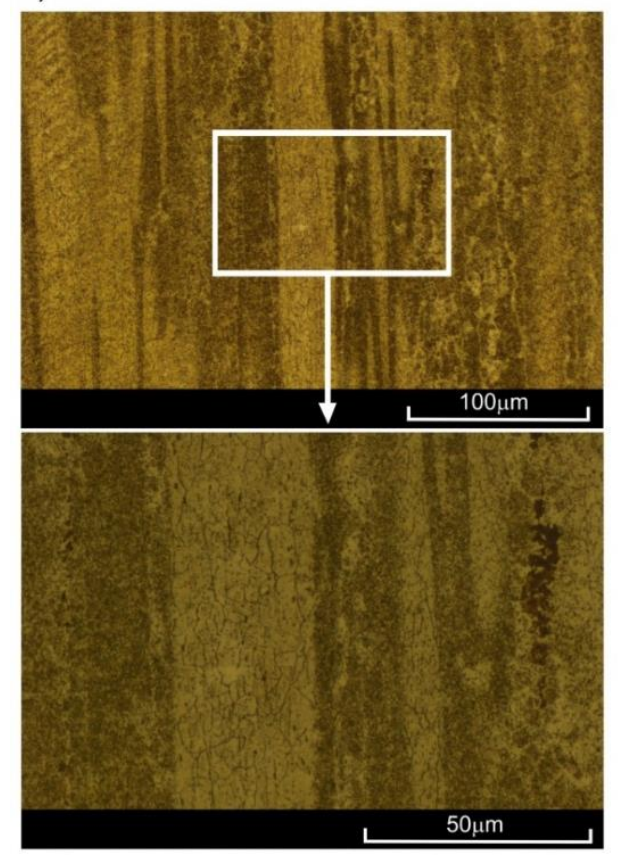

b)

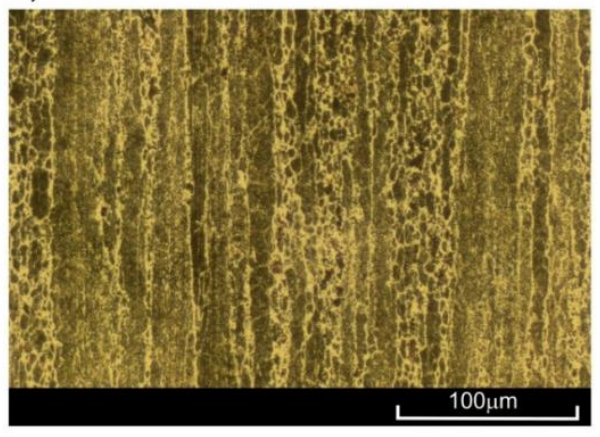

Figure 9. Microstructure of 2024 aluminium alloy subjected to creep at $300{ }^{\circ} \mathrm{C}$ for: (a) $\varepsilon_{\mathrm{s}}=0.4 \%$; (b) $\varepsilon_{\mathrm{t}}=2.3 \%$, cooled at ambient temperature.

The microstructure of the 2024 aluminium alloy subjected to creep at temperature of $200{ }^{\circ} \mathrm{C}$ until strain $\varepsilon_{\mathrm{S}}=0.6 \%$ was reached barely differed from the initial structure. Only single equiaxial grains could be observed, appearing mostly on the boundaries of parent grains in the vicinity of clusters of precipitation (Figure 8a). In these conditions, the advanced processes of recrystallization did not occur, which was confirmed by the results of the monotonic tensile tests-the curve $\varepsilon_{\mathrm{s}}=0.6 \%\left(200{ }^{\circ} \mathrm{C}\right)$ ran similarly to the curve of the input material (Figure 7). However, a very different picture was presented by the microstructure of alloy subjected to creep at $200{ }^{\circ} \mathrm{C}$ with a strain of $\varepsilon_{t}=2.3 \%$. Multiple fine equiaxial grains are visible in Figure $8 \mathrm{~b}$, with their layout corresponding to that of the preliminary grains. In conclusion, dynamic recrystallization (DRX) occurred in this case, which also led to the increase in plasticity (curve $\varepsilon_{\mathrm{t}}=2.3 \%$ in Figure 7 ). Both the appearance of the recrystallized grains throughout the whole volume of parent grains with no clear areas of nucleation and growth, and the fact that the analysed aluminium alloy is characterized by high stacking-fault energy (SFE) [8] indicate 
that continuous dynamic recrystallization (CDRX) occurred. The significant differences in the structure of alloy pre-deformed at $200{ }^{\circ} \mathrm{C}$ with various degrees of strain may also have been a result of the time of creep. At $\varepsilon_{\mathrm{s}}=0.6 \%$, both the strain level and time may have been insufficient for dynamic recrystallization to occur. Similar conclusions can be drawn by analysing results obtained for the alloy pre-deformed at $300{ }^{\circ} \mathrm{C}$ with strain of $\varepsilon_{\mathrm{s}}=0.4 \%$. Numerous lines of fine equiaxial grains could be observed in the alloy structure (Figure 9a). The share of the recrystallized structure was greater than in the sample pre-deformed at $200{ }^{\circ} \mathrm{C}$, as confirmed by the increase in plasticity (Figure 7 - curve $\varepsilon_{\mathrm{S}}=0.4 \%, 300{ }^{\circ} \mathrm{C}$ ). The increase in the degree of strain at $300{ }^{\circ} \mathrm{C}$ combined with longer period of creep led to the increase in the range of dynamic recrystallization-the recrystallized structure was visible in a large area of the analysed microstructure.

Creep tests at $200{ }^{\circ} \mathrm{C}$ and $300{ }^{\circ} \mathrm{C}$ were performed with a force lower than that corresponding with the yield stress, whereas they were performed with greater force at $100{ }^{\circ} \mathrm{C}$. Hence, in the latter case, the material properties after creep pre-deformation were mostly affected by the process of hardening connected to exceeded yield stress and relaxation of the sample. No evidence was found here that would indicate the process of recrystallization. Despite significant strains, the temperature of $100{ }^{\circ} \mathrm{C}$ was too low to initiate the process, hence the significant increase in the offset yield stress and the simultaneous decrease in elongation (Figure 7, Table 4).

The character of the fracture surface in samples pre-deformed at $200{ }^{\circ} \mathrm{C}$ was affected mostly by preliminary strain and the time for which the sample remained at increased temperature [42]. For the preliminary strain of $\varepsilon_{\mathrm{s}}=0.6 \%$, hardening of material occurred (with respect to as-extruded material), followed by subsequent softening. During the pre-deformation of $\varepsilon_{\mathrm{s}}=0.6 \%$, no significant strains occurred-only a few voids appeared, and the remnants after their clear shearing were spherical rather than elongated in the shape [41]. Several precipitations of intermetallic phases were observed. The lack of great numbers of voids after preliminary strain resulted in an increase in yield stress in the process of monotonic tension. However, the subsequent growth of these voids caused the material to be incapable of carrying shear stress, causing them to be cut easily and rapidly which could result in the reduction of ultimate tensile strength. It should be highlighted that the time during which the material remains at the elevated temperature has a great impact, also significantly affecting the values of the basic mechanical properties (e.g., [44-46]). In the case of pre-deformation at $200{ }^{\circ} \mathrm{C}$, this time varied significantly for $\varepsilon_{\mathrm{s}}=0.6 \%$ (ca. $30 \mathrm{~min}$ ) and $\varepsilon_{\mathrm{t}}=2.3 \%$ (ca. $300 \mathrm{~min}$ ). In the case of larger pre-strain $\left(\varepsilon_{\mathrm{t}}=2.3\right)$, the pores were joining and clearly deforming towards the direction of axial load in the central area of the cross section. After unloading, the pores which had not ruptured reassumed spherical shape and were ruptured during tension at room temperature (i.e., with smaller strain). The process of rupturing in the central area of the sample preceded ultimate shearing of the material. The fractures obtained in the samples with lower pre-deformation $\left(\varepsilon_{\mathrm{S}}\right)$ at temperatures of $100{ }^{\circ} \mathrm{C}$ and $200{ }^{\circ} \mathrm{C}$ were characterized by a large number of remnants (dimples) of small-sized pores (Figure 10).

In the case of greater pre-deformation $\left(\varepsilon_{\mathrm{t}}\right)$ at the same temperatures, small dimples covered much less surface in favour of large dimples. A similar effect was obtained by Lin et al. [47] by increasing temperature with the same stress or increasing stress at the same temperature during pre-deformation of the 2024 alloy. However, a similar effect of pore growth due to the increase in stress during creep rupture tests on the 2124 alloy at $260{ }^{\circ} \mathrm{C}$ was obtained by Li et al. [48]. The character of the fracture in the case of samples pre-deformed at $300{ }^{\circ} \mathrm{C}$ did not indicate any significant differences in terms of the value of this pre-deformation. The fracture initiation plane, perpendicular to the sample axis, was clearly marked, as was the shearing plane (Figure 10b). The share of the former in the total surface of the fracture was significantly lower than in the case of, for example, tension at $300{ }^{\circ} \mathrm{C}$. 
a)

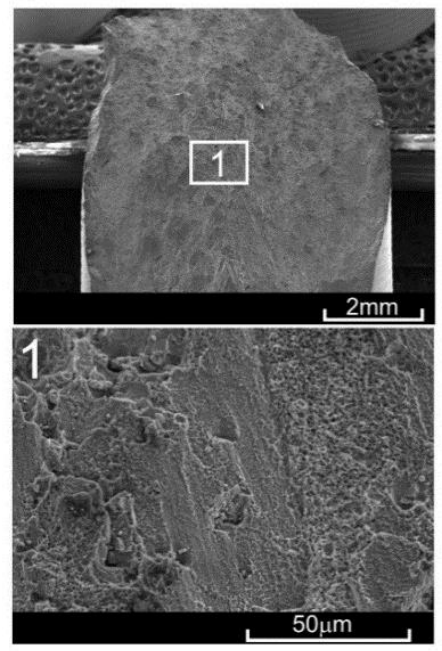

b)
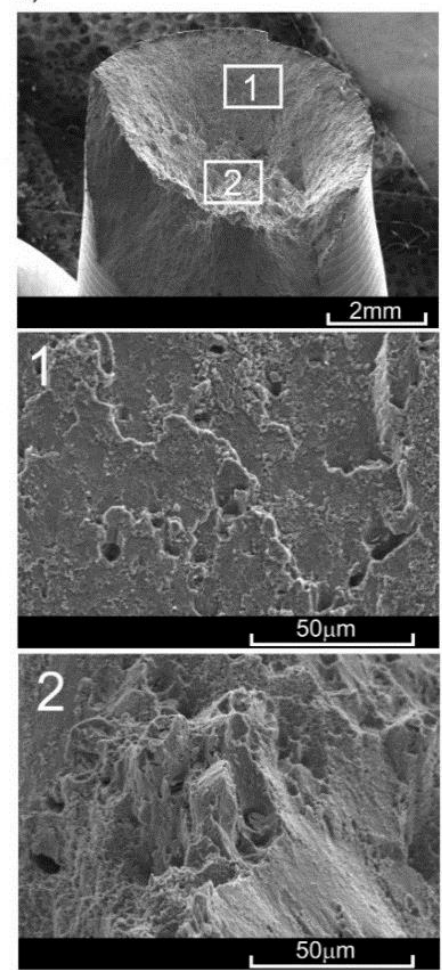

Figure 10. Surface of fractures obtained in monotonic tensile test at ambient temperature with pre-deformation for: (a) $\varepsilon_{\mathrm{s}}=10 \%$ at $100{ }^{\circ} \mathrm{C}$; (b) $\varepsilon_{\mathrm{s}}=0.4 \%$ at $300{ }^{\circ} \mathrm{C}$.

\subsection{Low-Cycle Fatigue (LCF) Tests}

Low-cycle fatigue tests were conducted on as-extruded material and material with pre-deformation at $200{ }^{\circ} \mathrm{C}$ and $300{ }^{\circ} \mathrm{C}$. Undamaged (as-extruded) material was chosen for comparison purpose. The material with pre-deformation-due to the possibility of investigating the impact of the DRX process on the cyclic properties of the material.

The fatigue tests were conducted in accordance with the conditions described in the last paragraph of the Section 2. Five degrees of total strain amplitude were selected (i.e., $0.02,0.01,0.008,0.005,0.0035$ ), and tests on each level were repeated three times. The description of the fatigue life was made using one of the most common models, namely the Manson-Coffin-Basquin model [49-52]:

$$
\varepsilon_{\mathrm{a}}=\varepsilon_{\mathrm{ae}}+\varepsilon_{\mathrm{ap}}=\frac{\sigma_{\mathrm{f}}^{\prime}}{E}\left(2 N_{\mathrm{f}}\right)^{b}+\varepsilon_{\mathrm{f}}^{\prime}\left(2 N_{\mathrm{f}}\right)^{c},
$$

where values $\varepsilon_{\mathrm{ae}}, \varepsilon_{\mathrm{ap}}$ are the amplitude of elastic and plastic strain respectively; $\sigma_{\mathrm{f}}^{\prime}, \varepsilon_{\mathrm{f}}^{\prime}$ are coefficients of fatigue strength and ductility; $b$ and $c$ are exponents of fatigue strength and ductility; $N_{\mathrm{f}}$ is the number of cycles to failure.

The cyclic properties of the material allowing for the identification of susceptibility to hardening or softening are described with the following formula (e.g., $[53,54])$ :

$$
\sigma_{\mathrm{a}}=K^{\prime}\left(\varepsilon_{\mathrm{ap}}\right)^{n^{\prime}},
$$

where $\sigma_{\mathrm{a}}$ is the stress amplitude; $n^{\prime}$ is the exponent of plastic hardening; $K^{\prime}$ is a material parameter.

In Figure 11, curves of fatigue life obtained for as-extruded material are compared with those obtained for material with pre-deformation at $200{ }^{\circ} \mathrm{C}$ and $300^{\circ} \mathrm{C}$. The values of the data from LCF tests, on the basis of which the diagrams in Figure 11 were built, are presented in Table 5. The number of cycles to failure is denoted by $N_{\mathrm{f}}$, the amplitude of the strain control variable by $\varepsilon_{\mathrm{a}}$, and the amplitude 
of the stress by $\sigma_{\mathrm{a}}$. Furthermore, only the cases in which a recrystallization process occurred were taken into account. As a result of pre-deformation, a significant increase in fatigue life occurred in the areas dominated by plastic deformation. This was particularly noticeable in the cases where the process of dynamic recrystallization was most efficient, namely for the temperature of $300{ }^{\circ} \mathrm{C}$ and significant strains of $\varepsilon_{t}=2.3 \%$ (Figure 11). At the same time, the fatigue life decreased in the areas dominated by elastic strains. For instance, the fatigue life for strain of $\varepsilon_{\mathrm{a}}=0.02$ for material pre-deformed at $\varepsilon_{\mathrm{s}}=0.4 \%$ and temperature of $300{ }^{\circ} \mathrm{C}$ increased from 7 to 66 cycles as compared with the as-extruded one, whereas in the case of material pre-deformed at $\varepsilon_{\mathrm{t}}=2.3 \%$ and the same temperature, fatigue life increased to 99 cycles [41]. In the case of the material pre-deformed at $\varepsilon_{\mathrm{t}}=2.3 \%$ at a temperature of $200{ }^{\circ} \mathrm{C}$, the fatigue life increased to 31 cycles. The transition number of cycles $2 N_{\mathrm{t}}$ increased as well (Figure 11).

a)

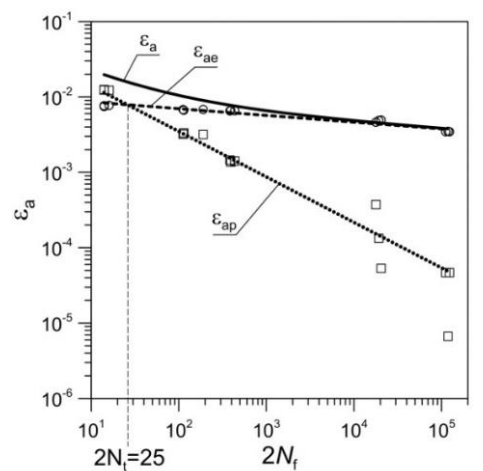

b)

c)
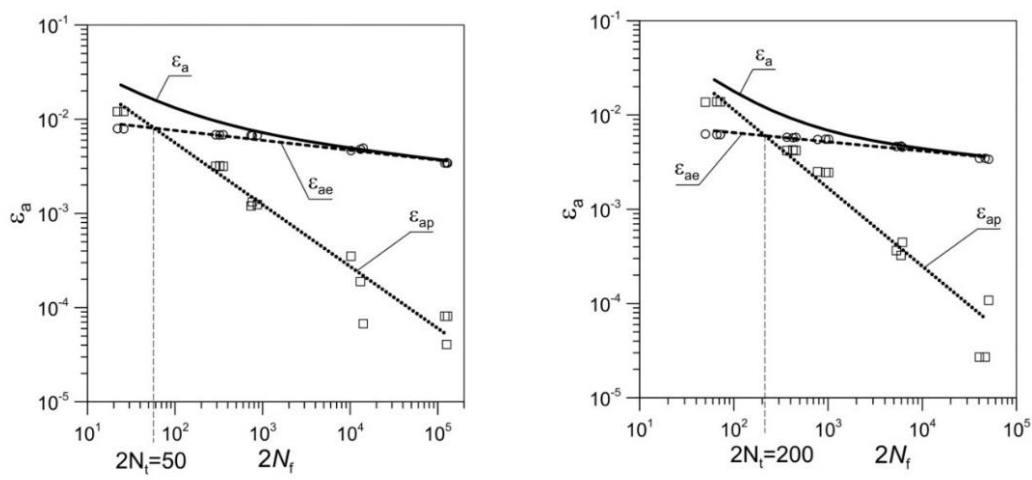

d)

e)
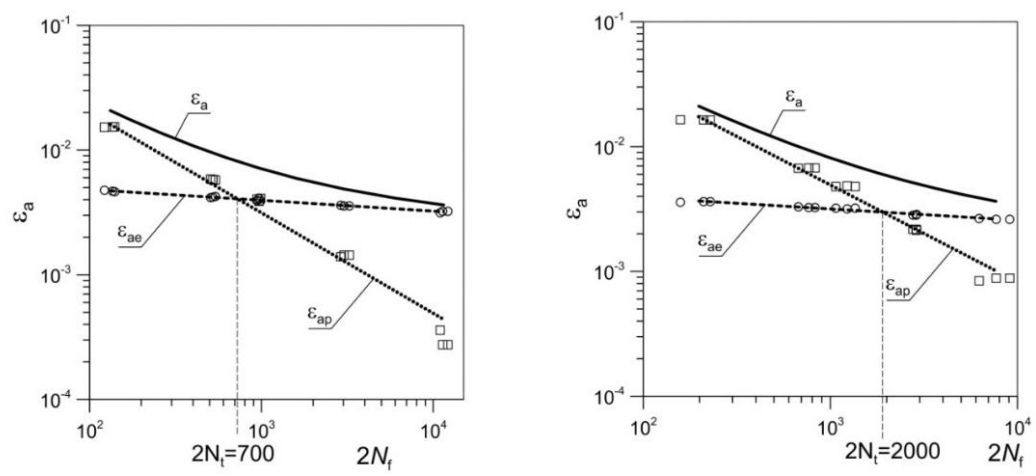

Figure 11. Fatigue life curves $\varepsilon_{\mathrm{a}}\left(2 N_{\mathrm{f}}\right)$ in logarithmic scale at ambient temperature obtained for EN AW-2024 aluminium alloy for (a) as-extruded material, and with pre-deformation at temperatures of (b) $200{ }^{\circ} \mathrm{C}\left(\varepsilon_{\mathrm{s}}=0.6 \%\right),(\mathbf{c}) 200{ }^{\circ} \mathrm{C}\left(\varepsilon_{\mathrm{t}}=2.3 \%\right),(\mathbf{d}) 300{ }^{\circ} \mathrm{C}\left(\varepsilon_{\mathrm{s}}=0.4 \%\right)$, and (e) $300{ }^{\circ} \mathrm{C}\left(\varepsilon_{\mathrm{t}}=2.3 \%\right)$. 
Table 5. Low-cycle fatigue (LCF) data obtained for as-extruded material and material with pre-deformation at $200{ }^{\circ} \mathrm{C}$ and $300{ }^{\circ} \mathrm{C}$ [42].

\begin{tabular}{|c|c|c|c|c|c|c|c|c|}
\hline \multirow{2}{*}{$\varepsilon_{\mathbf{a}}$} & \multicolumn{2}{|c|}{ As-Extruded } & \multicolumn{3}{|c|}{ Pre-Deformed at $200{ }^{\circ} \mathrm{C}$} & \multicolumn{3}{|c|}{ Pre-Deformed at $300{ }^{\circ} \mathrm{C}$} \\
\hline & $N_{\mathrm{f}}$ & $\sigma_{\mathrm{a}}(\mathrm{MPa})$ & $\varepsilon_{\mathrm{S}}\left(\varepsilon_{\mathrm{t}}\right)(\%)$ & $N_{\mathrm{f}}$ & $\sigma_{\mathrm{a}}(\mathrm{MPa})$ & $\varepsilon_{\mathrm{s}}\left(\varepsilon_{\mathrm{t}}\right)(\%)$ & $N_{\mathrm{f}}$ & $\sigma_{\mathrm{a}}(\mathrm{MPa})$ \\
\hline \multirow{2}{*}{0.02} & \multirow[b]{2}{*}{7} & \multirow{2}{*}{571} & $\varepsilon_{\mathrm{S}}=0.6$ & 12 & 587 & $\varepsilon_{\mathrm{S}}=0.4$ & 66 & 333 \\
\hline & & & $\varepsilon_{\mathrm{t}}=2.3$ & 31 & 461 & $\varepsilon_{\mathrm{t}}=2.3$ & 99 & 262 \\
\hline \multirow{2}{*}{0.01} & \multirow{2}{*}{69} & \multirow{2}{*}{507} & $\varepsilon_{\mathrm{S}}=0.6$ & 162 & 505 & $\varepsilon_{\mathrm{S}}=0.4$ & 261 & 298 \\
\hline & & & $\varepsilon_{\mathrm{t}}=2.3$ & 208 & 428 & $\varepsilon_{\mathrm{t}}=2.3$ & 379 & 237 \\
\hline \multirow{2}{*}{0.008} & \multirow{2}{*}{202} & \multirow{2}{*}{494} & $\varepsilon_{\mathrm{S}}=0.6$ & 395 & 499 & $\varepsilon_{\mathrm{S}}=0.4$ & 483 & 283 \\
\hline & & & $\varepsilon_{\mathrm{t}}=2.3$ & 455 & 409 & $\varepsilon_{t}=2.3$ & 610 & 232 \\
\hline \multirow{2}{*}{0.005} & \multirow{2}{*}{9576} & \multirow{2}{*}{361} & $\varepsilon_{\mathrm{S}}=0.6$ & 6235 & 355 & $\varepsilon_{\mathrm{S}}=0.4$ & 1528 & 254 \\
\hline & & & $\varepsilon_{\mathrm{t}}=2.3$ & 2906 & 342 & $\varepsilon_{\mathrm{t}}=2.3$ & 1420 & 206 \\
\hline \multirow{2}{*}{0.0035} & \multirow{2}{*}{58,965} & \multirow{2}{*}{260} & $\varepsilon_{\mathrm{S}}=0.6$ & 62,739 & 254 & $\varepsilon_{\mathrm{S}}=0.4$ & 5747 & 227 \\
\hline & & & $\varepsilon_{\mathrm{t}}=2.3$ & 22,914 & 255 & $\varepsilon_{\mathrm{t}}=2.3$ & 3836 & 191 \\
\hline
\end{tabular}

With the constant value of control variable $\varepsilon_{\mathrm{a}}$, the increase in fatigue life was observed to come at the cost of decline in fatigue strength (Figure 12a). This was again particularly visible in the cases where recrystallization covered the largest number of grains (i.e., for pre-deformation at $300{ }^{\circ} \mathrm{C}$ ). This applied to both low-cycle and high-cycle loads. In the case of control variable $\varepsilon_{\mathrm{a}}=0.02$ and material pre-deformed at $\varepsilon_{\mathrm{s}}=0.4 \%$ and temperature of $300{ }^{\circ} \mathrm{C}$, strength decreased from $571 \mathrm{MPa}$ to $333 \mathrm{MPa}$ (by ca. $40 \%$ ), whereas it decreased to $262 \mathrm{MPa}$ (by ca. $54 \%$ ) in the case of material pre-deformed at $\varepsilon_{\mathrm{t}}=2.3 \%$ at the same temperature [41]. The decrease in the fatigue life for the material pre-deformed at $200{ }^{\circ} \mathrm{C}\left(\varepsilon_{\mathrm{t}}=2.3 \%\right)$ with the control variable of $\varepsilon_{\mathrm{a}}=0.0035$ proceeded while retaining the same level of strength (Figure 12a).

a)

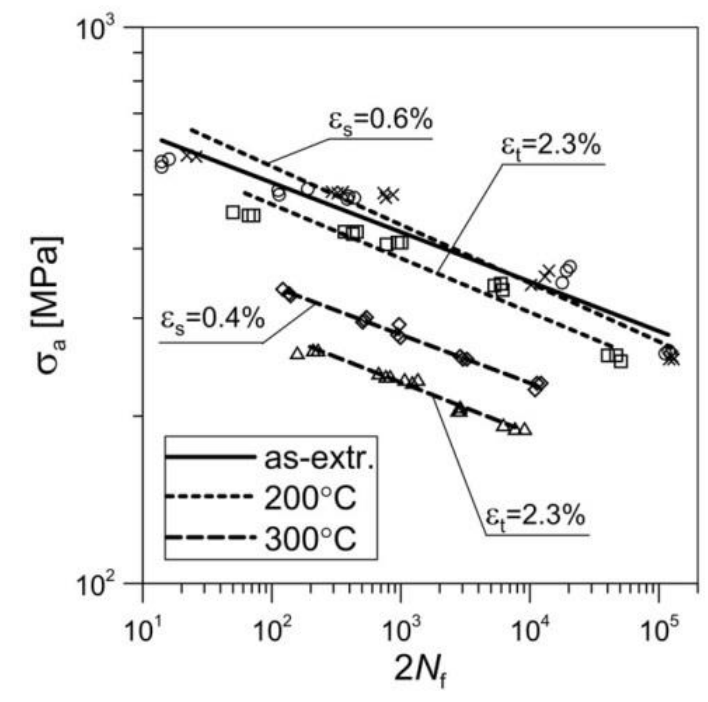

b)

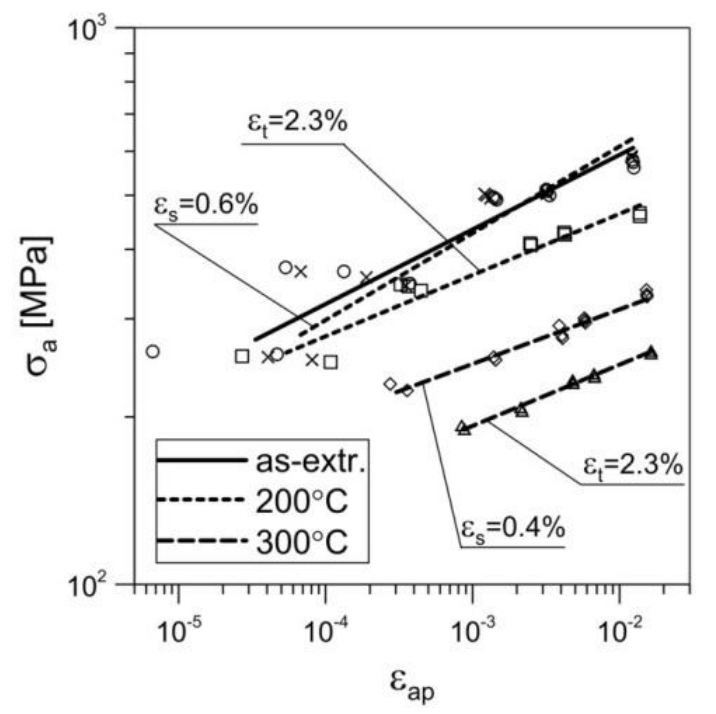

Figure 12. (a) Fatigue life curves $\sigma_{\mathrm{a}}\left(2 N_{\mathrm{f}}\right)$ in logarithmic scale and (b) curves of cyclic strain $\sigma_{\mathrm{a}}\left(\varepsilon_{\mathrm{ap}}\right)$ at ambient temperature as obtained for samples of 2024 aluminium alloy with pre-deformation at various temperatures and with varying degrees of strain.

Figure $12 \mathrm{~b}$ depicts the change in the cyclic plasticity of the pre-deformed material in comparison with the as-extruded material. The dynamic recrystallization led to improved plasticity and an increase of the plastic flow phase during cyclic loading (Figure 13). 
a)

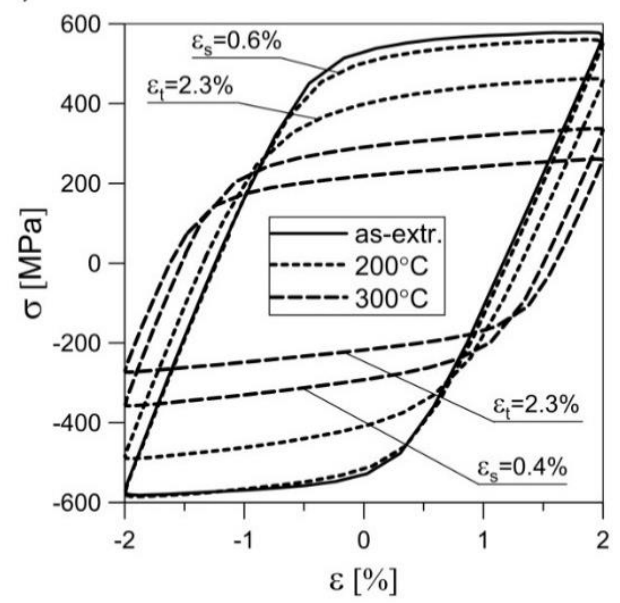

b)

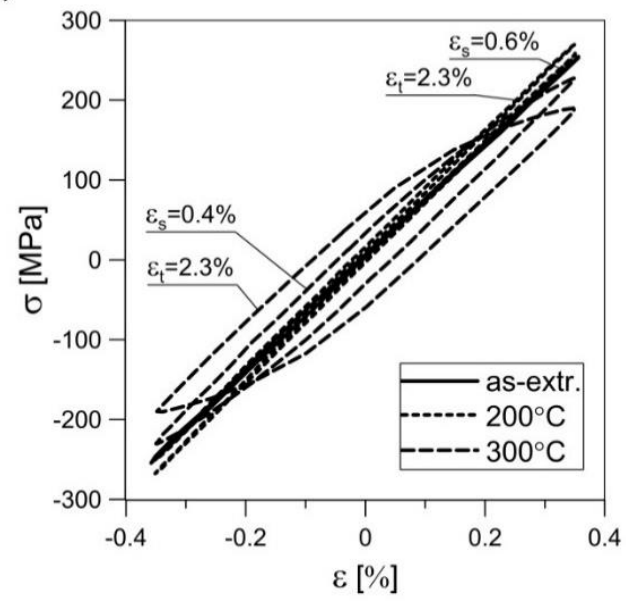

Figure 13. Stabilized hysteresis loops obtained for EN AW-2024 aluminium alloy subjected to creep pre-deformation at various temperatures and with varying degrees of strain: (a) $\varepsilon_{\mathrm{a}}=0.02 ;(\mathbf{b}) \varepsilon_{\mathrm{a}}=0.0035$.

However, this came at the cost of a reduction in the fatigue strength. As a result, the material in which recrystallization proved to be most efficient at low loading amplitudes (0.0035) had a clear wide hysteresis loop. The loops of the less-recrystallized material were very narrow-there were no plastic deformations detected. It should be noted that the pre-deformation at $\varepsilon_{\mathrm{s}}=0.6 \%$ at $200{ }^{\circ} \mathrm{C}$ only slightly affected the cyclic properties of the material as compared to the as-extruded material. This applied to both small and large values of the control variable $\varepsilon_{\mathrm{a}}$. This is particularly interesting considering the fact that the basic mechanical parameters of the material changed significantly (see Table 4). A different situation could be observed for the material with pre-deformation of $\varepsilon_{\mathrm{t}}=2.3 \%$ at $200{ }^{\circ} \mathrm{C}$. Here one may notice a significant change in both cyclic and monotonic behaviour.

The process of dynamic recrystallization also led to a decrease in the material's cyclic hardening capability (Figure 14). As-extruded material indicated clear susceptibility to high (ca. 20\%) cyclic hardening [41]. As a result of the pre-deformation at the temperature of $300{ }^{\circ} \mathrm{C}$, on both levels of strain, the cyclic strengthening was insignificant. In the range of strains between $0 \%$ and $2 \%$, the material was practically cyclically stable, whereas pre-deformation at the temperature of $200{ }^{\circ} \mathrm{C}$ and strain level of $\varepsilon_{\mathrm{t}}=2.3 \%$ led to cyclic softening of the material. Metallographic sections of the samples subjected to fatigue tests were also analysed. However, these did not demonstrate any significant differences in comparison with the sections of the samples previously subjected to pre-strain at increased temperature.

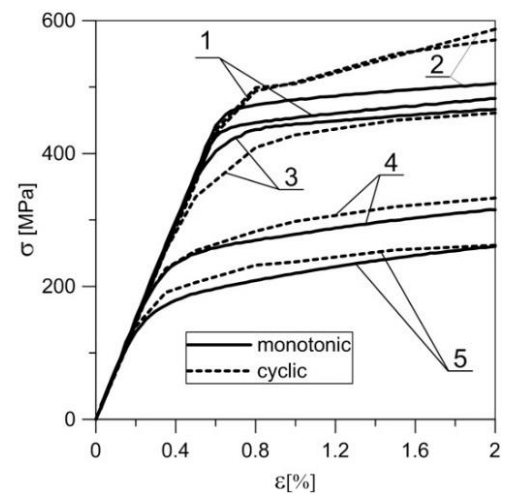

Figure 14. Curves of monotonic and cyclic tension at ambient temperature obtained for EN AW-2024 aluminium alloy samples pre-deformed at various temperatures and with varying degrees of strain: 1 -as-extruded; $2-200{ }^{\circ} \mathrm{C}, \varepsilon_{\mathrm{s}}=0.6 \% ; 3-200{ }^{\circ} \mathrm{C}, \varepsilon_{\mathrm{t}}=2.3 \% ; 4-300{ }^{\circ} \mathrm{C}, \varepsilon_{\mathrm{s}}=0.4 \% ; 5-300{ }^{\circ} \mathrm{C}, \varepsilon_{\mathrm{t}}=2.3 \%$. 
This paper presents results of our study on the influence of preliminary creep at elevated temperature on the monotonic and cyclic properties of 2024 aluminium alloy. In the case of low temperature $\left(100^{\circ} \mathrm{C}\right)$ and high strain value, these properties were determined to be affected mostly by mechanical hardening of the material. In the case of higher temperatures $\left(200^{\circ} \mathrm{C}, 300^{\circ} \mathrm{C}\right)$, the possibility of continuous dynamic recrystallization gained significance. This possibility occurred even at low loading speeds (i.e., $0.0015 / \mathrm{s}$ ), although in the monotonic tension process only at the temperature of $300{ }^{\circ} \mathrm{C}$. In the case of creep at $200{ }^{\circ} \mathrm{C}$, the recrystallization process occurred only in cases of loading until a greater level of pre-strain $\varepsilon_{\mathrm{t}}=2.3 \%$ was achieved. In the case of creep at $300{ }^{\circ} \mathrm{C}$, this process occurred for preliminary strain of both $\varepsilon_{\mathrm{s}}=0.4 \%$ and $\varepsilon_{\mathrm{t}}=2.3 \%$. However, in the latter case, the process covered a noticeably greater number of grains.

\section{Conclusions}

Creep pre-deformation at various temperatures allows for the shaping of both monotonic and cyclic properties of the material. The selection of proper parameters of this pre-deformation (e.g., temperature, loading force, or strain level) allows for the improvement of mechanical parameters. This relates to the effectiveness of dynamic recrystallization. The effect of dynamic recrystallization can be summarized as follows:

1. In the case of the creep pre-deformation at $300{ }^{\circ} \mathrm{C}$, the increase of the value of pre-deformation could also be observed to worsen the basic mechanical parameters in comparison with as-extruded material. However, in the case of the pre-deformation at $200{ }^{\circ} \mathrm{C}$ and low values of preliminary strain, the increased yield stress was obtained accompanied by a decrease in the ultimate tensile strength. On the other hand, greater preliminary strains led to the worsening of both yield and ultimate tensile strength.

2. A significant increase in the strain-controlled fatigue life was observed in the area dominated by plastic deformation in the samples with creep pre-deformation at $300^{\circ} \mathrm{C}$, where clear dynamic recrystallization occurred. This applied to the samples pre-deformed to both values of strain $\left(\varepsilon_{\mathrm{S}}=0.4 \%\right.$ and $\left.\varepsilon_{\mathrm{t}}=2.3 \%\right)$, although the improvement was more significant for $\varepsilon_{\mathrm{t}}$.

3. The inverse situation could be observed in the area dominated by elastic strains. In this case, the fatigue life decreased in comparison with as-extruded material.

4. The improvement of the fatigue life was determined to take place at the cost of the decline of its fatigue strength at constant value of the strain-control variable. Such regularity was most visible in the material pre-deformed at the temperature of $300^{\circ} \mathrm{C}$, and was much less visible at $200{ }^{\circ} \mathrm{C}$.

During creep at elevated temperatures, a continuous dynamic recrystallization (CDRX) occurs. The degree of recrystallization increases with the increase in temperature and strain level, which significantly affects the plasticity of the material.

Author Contributions: Conceptualization, A.S.; Formal Analysis, M.G.-D.; Investigation, A.T.; Writing-Original Draft Preparation, A.T.

Funding: This research was funded by the Ministry of Science and Higher Education of Poland (research project No S/WM/4/2017) and realized in Bialystok University of Technology.

Conflicts of Interest: The authors declare no conflict of interest.

\section{References}

1. Amrouche, A.; Mesmacque, G.; Garcia, S.; Talha, A. Cold expansion effect on the initiation and propagation of the fatigue crack. Int. J. Fatigue 2003, 25, 949-954. [CrossRef]

2. Chakherlou, T.N.; Aghdam, A.B.; Akbari, A.; Saeedi, K. Analysis of cold expanded fastener holes subjected to short time creep: Finite element modelling and fatigue tests. Mater. Des. 2010, 31, 2858-2866. [CrossRef] 
3. Karakaş, Ő.; Szusta, J. Monotonic and low cycle fatigue behaviour of 2024-T3 aluminium alloy between room temperature and $300^{\circ} \mathrm{C}$ for designing VAWT components. Fatigue Fract. Eng. Mater. Struct. 2016, 39, 95-109. [CrossRef]

4. Xie, J.; Zhu, Y.; Bian, F.; Liu, C. Dynamic recovery and recrystallization mechanisms during ultrasonic spot welding of Al-Cu-Mg alloy. Mater. Charact. 2017, 132, 145-155. [CrossRef]

5. Son, K.-T.; Lee, J.-W.; Jung, T.-K.; Choi, H.-J.; Kim, S.-W.; Kim, S.K.; Yoon, Y.-O.; Hyun, S.-K. Evaluation of Dynamic Recrystallization Behaviors in Hot-Extruded AA5083 Through Hot Torsion Tests. Met. Mater. Int. 2016, 23, 68-75. [CrossRef]

6. Maizza, G.; Pero, R.; Richetta, M.; Montanari, R. Continuous dynamic recrystallization (CDRX) model for aluminum alloys. J. Mater. Sci. 2018, 53, 4563-4573. [CrossRef]

7. Gourdet, S.; Montheillet, F. An experimental study of the recrystallization mechanism during hot deformation of aluminium. Mater. Sci. Eng. A 2000, 283, 274-288. [CrossRef]

8. Huang, K.; Loge, R.E. A review of dynamic recrystallization phenomena in metallic materials. Mater. Des. 2016, 111, 548-574. [CrossRef]

9. Jazaeri, H.; Humphreys, F.J. The transition from discontinuous to continuous recrystallization in some aluminium alloys II-Annealing behaviour. Acta Mater. 2014, 52, 3251-3262. [CrossRef]

10. Lin, Y.; Liu, W.; Wang, L.; Lavernia, E.J. Ultra-fine grained structure in Al-Mg induced by discontinuous dynamic recrystallization under moderate straining. Mater. Sci. Eng. A 2013, 573, 197-204. [CrossRef]

11. Shi, C.J.; Lai, J.; Chen, X.G. Microstructural evolution and dynamic softening mechanisms of Al-Zn-Mg-Cu alloy during hot compressive deformation. Mater. Sci. Eng. A 2014, 7, 244-264. [CrossRef] [PubMed]

12. Tsivoulas, D.; Prangnell, P.B. The effect of $\mathrm{Mn}$ and $\mathrm{Zr}$ dispersoid-forming additions on recrystallization resistance in Al-Cu-Li AA2198 sheet. Acta Mater. 2014, 77, 1-16. [CrossRef]

13. Hirata, T.; Higashi, K. The investigation on microcavitation behavior during dynamic recrystallization in PM7475 aluminum alloy. Scr. Mater. 2002, 47, 1-6. [CrossRef]

14. Hirata, T.; Mukai, T.; Saito, N.; Tanabe, S.; Kohzu, M.; Higashi, K. Experimental prediction of deformation mechanism after continuous dynamic recrystallization in superplastic PM7475. J. Mater. Sci. 2003, 38, 3925-3932. [CrossRef]

15. Li, J.-C.; Xie, Z.-Y.; Li, S.-P.; Zang, Y.-Y. Modeling on dynamic recrystallization of aluminium alloy 7050 during hot compression based on cellular automaton. J. Cent. South Univ. 2016, 23, 497-507. [CrossRef]

16. Li, D.-F.; Zhang, D.-Z.; Liu, S.-D.; Shan, Z.-J.; Zhang, X.-M.; Wang, Q.; Han, S.-Q. Dynamic recrystallization behavior of 7085 aluminum alloy during hot deformation. Trans. Nonferr. Met. Soc. China 2016, 26, 1491-1497. [CrossRef]

17. Chen, G.; Chen, L.; Zhao, G.; Zhang, C.; Cui, W. Microstructure analysis of an Al-Zn-Mg alloy during porthole die extrusion based on modeling of constitutive equation and dynamic recrystallization. J. Alloys Compd. 2017, 710, 80-91. [CrossRef]

18. Agarwal, S.; Krajewski, P.E.; Briant, C.L. Dynamic recrystallization of AA5083 at 450C, the effects of strain rate and particle size. Metall. Mater. Trans. A 2008, 39, 1277-1289. [CrossRef]

19. Hu, H.E.; Zhen, L.; Zhang, B.Y.; Yang, L.; Chen, J.Z. Microstructure characterization of 7050 aluminum alloy during dynamic recrystallization and dynamic recovery. Mater. Charact. 2008, 59, 1185-1189. [CrossRef]

20. Dougherty, L.M.; Robertson, I.M.; Vetrano, J.S. Direct observation of the behavior of grain boundaries during continuous dynamic recrystallization in an Al-4Mg-0.3Sc alloy. Acta Mater. 2003, 51, 4376-4378. [CrossRef]

21. Ihara, K.; Miura, Y. Dynamic recrystallization in Al-Mg-Sc alloys. Mater. Sci. Eng. A 2004, 387-389, 647-650. [CrossRef]

22. Adachi, H.; Yammoto, Y.; Nakanishi, H.; Aida, T.; Imaoka, M.; Kusui, J. Effect of dispersed Al3Sc particles on dynamic recrystallization in PM 7000 series alloys. Trans. Indian Inst. Met. 2009, 62, 159-162. [CrossRef]

23. Ko, B.-C.; Yoo, Y.-C. Prediction of dynamic recrystallization condition by deformation efficiency for Al 2024 composite reinforced with SiC particle. J. Mater. Sci. 2000, 35, 4073-4077. [CrossRef]

24. Gholinia, A.; Humphreys, F.J.; Prangnell, P.B. Production of ultra-fine grain microstructures in Al-Mg alloys by conventional rolling. Acta Mater. 2002, 52, 4461-4476. [CrossRef]

25. Kaibyshev, R.; Shipilova, K.; Musin, F.; Motohashi, Y. Continuous dynamic recrystallization in an Al-Li-Mg-Sc alloy during equal-channel angular extrusion. Mater. Sci. Eng. A 2005, 396, 341-351. [CrossRef] 
26. Gholinia, A.; Prangnell, P.B.; Markushev, M.V. The effect of strain path on the development of deformation structures in severely deformed aluminium alloys processed by ECAE. Acta Mater. 2000, 48, 1115-1130. [CrossRef]

27. Mazurina, I.; Sakai, T.; Miura, H.; Sitdikov, O.; Kaibyshev, R. Grain refinement in aluminum alloy 2219 during ECAP at $250{ }^{\circ}$ C. Mater. Sci. Eng. A 2008, 473, 297-305. [CrossRef]

28. Mazurina, I.; Sakai, T.; Miura, H.; Sitdikov, O.; Kaibyshev, R. Effect of deformation temperature on microstructure evolution in aluminum alloy 2219 during hot ECAP. Mater. Sci. Eng. A 2008, 486, 662-671. [CrossRef]

29. Nikulin, I.; Kaibyshev, R.; Sakai, T. Superplasticity in a 7055 aluminum alloy processed by ECAE and subsequent isothermal rolling. Mater. Sci. Eng. A 2005, 407, 62-70. [CrossRef]

30. Sitdikov, O.; Sakai, T.; Miura, H.; Hama, C. Temperature effect on fine-grained structure formation in high-strength Al alloy 7475 during hot severe deformation. Mater. Sci. Eng. A 2009, 516, 180-188. [CrossRef]

31. Sauvage, X.; Murashkin, M.Y.; Straumal, B.B.; Bobruk, E.V.; Valiev, R.Z. Ultrafine Grained Structures Resulting from SPD-Induced Phase Transformation in Al-Zn Alloys. Adv. Eng. Mater. 2015, 17, 1821-1827. [CrossRef]

32. Straumal, B.B.; Baretzky, B.; Mazilkin, A.A.; Phillipp, F.; Kogtenkova, O.A.; Volkov, M.N.; Valiev, R.Z. Formation of nanograined structure and decomposition of supersaturated solid solution during high pressure torsion of Al-Zn and Al-Mg alloys. Acta Mater. 2004, 52, 4469-4478. [CrossRef]

33. Straumal, B.B.; Kilmametov, A.R.; Korneva, A.; Mazilkin, A.A.; Straumal, P.B.; Zięba, P.; Baretzky, B. Phase transitions in Cu-based alloys under high pressure torsion. J. Alloys Compd. 2017, 707, 20-26. [CrossRef]

34. Kilmametov, A.R.; Ivanisenko, Y.; Mazilkin, A.A.; Straumal, B.B.; Gornakova, A.S.; Fabrichnaya, O.B.; Kriegel, M.J.; Rafaja, D.; Hahn, H. The $\alpha \rightarrow \omega$ and $\beta \rightarrow \omega$ phase transformations in Ti-Fe alloys under high-pressure torsion. Acta Mater. 2018, 144, 337-351. [CrossRef]

35. Inspection Certificate according to EN 10204/3.1. (Received from the Seller). Available online: http: / / nst.no/dokumenter/sertifikater/429110.pdf (accessed on 22 May 2018).

36. Tomczyk, A.; Koniuszewski, R. Construction of a System for Measuring Sample Elongations at Elevated Temperatures Using Devices Intended for Work at Room Temperature. Patent No. PL 68955 Y1, 31 March 2017. (In Polish)

37. ASTM E606. Standard Test Method for Strain-Controlled Fatigue Testing; ASTM: West Conshohocken, PA, USA, 2012.

38. EN ISO 6892-1: 2016. Metallic Materials, Tensile Testing-Part 1: Method of Test at Room Temperature; ISO: Geneva, Switzerland, 2016.

39. EN ISO 6892-2: 2011. Metallic Materials, Tensile Testing-Part 2: Method of Test at Elevated Temperature; ISO: Geneva, Switzerland, 2011.

40. Derpenski, Ł.; Seweryn, A. Ductile fracture of EN-AW 2024 aluminum alloy specimens with notches under biaxial loading. Part 2-Numerical research and ductile fracture criterion. Theor. Appl. Fract. Mech. 2016, 84, 203-2014. [CrossRef]

41. Tomczyk, A.; Seweryn, A. Fatigue life of EN AW-2024 alloy accounting for creep pre-deformation at elevated temperature. Int. J. Fatigue 2017, 103, 488-507. [CrossRef]

42. Tomczyk, A.; Seweryn, A.; Doroszko, M. Monotonic behaviour of typical Al-Cu-Mg alloy pre-strained at elevated temperature. J. Theor. Appl. Mech. 2018. accepted.

43. EN ISO 204: 2009. Metallic Materials, Uniaxial Creep Testing in Tension: Method of Test; ISO: Geneva, Switzerland, 2009.

44. Ro, Y.J.; Begley, M.R.; Gangloff, R.P.; Agnew, S.R. Effect of aging on scale-dependent plasticity in aluminum alloy 2024. Mater. Sci. Eng. A 2006, 435-436, 333-342. [CrossRef]

45. Li, C.; Wan, M.; Wu, X.-D.; Huang, L. Constitutive equations in creep of 7B04 aluminum alloys. Mater. Sci. Eng. A 2010, 527, 3623-3629. [CrossRef]

46. Guo, W.; Yang, M.; Zheng, Y.; Zhang, X.; Li, H.; Wen, X.; Zhang, J. Influence of elastic tensile stress on aging process in an Al-Zn-Mg-Cu alloy. Mater. Lett. 2013, 106, 14-17. [CrossRef]

47. Lin, Y.C.; Jiang, Y.-Q.; Xia, Y.-C.; Zhang, X.-C.; Zhou, H.-M.; Deng, J. Effects of creep-aging processing on the corrosion resistance and mechanical properties of an Al-Cu-Mg alloy. Mater. Sci. Eng. A 2014, 605, $192-202$. [CrossRef]

48. Li, L.-T.; Lin, Y.C.; Zhou, H.-M.; Jiang, Y.-Q. Modeling the high temperature creep behaviors of 7075 and 2124 aluminum alloys by continuum damage mechanics model. Comput. Mater. Sci. 2013, 73, 72-78. [CrossRef] 
49. Manson, S.S. Behavior of Materials under Conditions of Thermal Stress; Report No. NACA TN-2933; National Advisory Committee for Aeronautics: Kitty Hawk, NC, USA, 1954.

50. Coffin, L.F. A study of the effect of cyclic thermal stresses on a ductile metal. Trans. ASME 1954, 76, 931-950.

51. Basquin, O.H. The exponential law of endurance tests. Am. Soc. Test. Mater. Proc. 1910, 10, 625-630.

52. Szusta, J.; Seweryn, A. Experimental study of the low-cycle fatigue life under multiaxial loading of aluminum alloy EN AW-2024-T3 at elevated temperatures. Int. J. Fatigue 2017, 96, 28-42. [CrossRef]

53. El Gharad, A.; Zedira, H.; Azari, Z.; Pluvinage, G. A synergistic creep fatigue failure model damage (case of the alloy Z5NCTA at $550{ }^{\circ} \mathrm{C}$ ). Eng. Fract. Mech. 2006, 73, 750-770. [CrossRef]

54. Falkowska, A.; Seweryn, A.; Tomczyk, A. Fatigue life and strength of 316L sintered steel of varying porosity. Int. J. Fatigue 2018, 111, 161-176. [CrossRef]

(C) 2018 by the authors. Licensee MDPI, Basel, Switzerland. This article is an open access article distributed under the terms and conditions of the Creative Commons Attribution (CC BY) license (http:/ / creativecommons.org/licenses/by/4.0/). 